\title{
THE INSULIN TOLERANCE TEST IN PATIENTS WITH ESSENTIAL HYPERTENSION 1, 2
}

\author{
By I. ARTHUR MIRSKY, STANLEY M. KAPLAN, CLARENCE J. PODORE, AND \\ ROBERT H. BROH-KAHN
}

\begin{abstract}
(From The May Institute for Medical Research, The Jewish Hospital, and the Departments of Psychiatry and Medicine, University of Cincinnati, Cincinnati)
\end{abstract}

(Received for publication September 1, 1949)

The curve of the blood sugar changes subsequent to the injection of insulin is divisible into a phase characterized by a progressive decrease in the blood sugar followed by a phase characterized by a restoration of the blood sugar to its preinjection level. Although the role of the various factors which influence the hypoglycemic action of insulin is imperfectly understood, it is well established that the anterior pituitary gland and the adrenal cortex exert a profound effect on the first phase of the post-insulin blood sugar curve. Thus, the administration of various hormones of the anterior pituitary gland $(1,2)$ and of the adrenal cortex (2) inhibits the hypoglycemic effect of insulin, whereas ablation of these glands results in an increase in this effect of insulin (3). In accord are the decreased sensitivity to insulin of the patient with hyperactivity of the anterior pituitary or of the adrenal gland (4) and the increased sensitivity to insulin of the patient with a decreased activity of one or the other gland (4).

The restitution of the blood sugar from the hypoglycemic to the preinjection level appears to be dependent primarily upon the responsiveness of the sympathico-medulloadrenal system and to some degree also upon the activity of the anterior pituitary and adrenal cortex. Thus, a marked delay in the restitution of the blood sugar level after the administration of insulin occurs after excision of one adrenal gland and denervation of the other or after denervation of both glands in the cat (5), rabbit (6) and $\operatorname{dog}(7)$, and after sympathectomy in the cat (8), dog (9) and man (10). The observation that the production of hypoglycemia results in an increased activity of the sympathico-

\footnotetext{
1 Presented in part before the meeting of the American Society for Clinical Investigation, May 1949.

2 This investigation was aided in part by a grant from the Division of Research Grants, National Institutes of Health, U. S. Public Health Service.
}

medulloadrenal system and the liberation of epinephrine into the circulation (5) makes it appear probable that the restoration of the blood sugar is accomplished by means of the glycogenolytic action of epinephrine. However, others have suggested that the restoration of the blood sugar is dependent also upon the responsiveness of the anterior pituitary and the adrenal cortex. For that reason, Fraser, Albright, and Smith (4) advocated the use of a standardized insulin tolerance test as a measure of the activity of these glands.

The mechanisms which appear to regulate the response of the blood sugar to the injection of insulin have been implicated also in the etiology of essential hypertension in man. It has been postulated by some authorities that the sympathicomedulloadrenal system is involved either in the production or maintenance of the hypertension (11) whereas others have suggested that the anterior pituitary gland and the adrenal cortex may be involved in the genesis of this disease (12). The beneficial effect of sympathectomy in some patients with essential hypertension (13) lends support to the neurogenic hypothesis. On the other hand, the incidence of hypertension in patients with hyperpituitarism and hyperadrenalcorticalism, the hypotension of patients with Simmonds' and Addison's disease, the hypotensive effect of hypophysectomy (14) or adrenalectomy (15) in experimental renal hypertension, and the restoration of the hypertension by adrenocorticotrophic hormone (14) or adrenal cortical hormone (15) administration to such animals are facts which favor an endocrine control of blood pressure.

Since the blood sugar response to the administration of insulin is influenced by both the neural and endocrine factors, it would appear that the insulin tolerance test could be utilized to gauge the activity of these factors in the patient with hypertension. 
TABLE I

Insulin tolerance lest in normotensive and hypertensive subjects

\begin{tabular}{|c|c|c|c|c|}
\hline Factor* & $\begin{array}{l}\text { Normo- } \\
\text { tensive }\end{array}$ & $\begin{array}{l}\text { Hyper- } \\
\text { tensive }\end{array}$ & $' t$ ' & $\begin{array}{l}\text { Significance of } \\
\text { differences }\end{array}$ \\
\hline Number of patients & 21 & 19 & & \\
\hline Age & $40.7 \pm 20.9$ & 47. \pm 11.7 & 1.142 & Not significant \\
\hline Weight (kg.) & $64.1 \pm 12.9$ & $63.6 \pm 13.9$ & 0.105 & Not significant \\
\hline $\begin{array}{l}\text { Systolic pressure } \\
(\mathrm{mm} . \mathrm{Hg})\end{array}$ & $115.8 \pm 10.1$ & 190. \pm 39.9 & 8.255 & $\mathrm{p}<0.001$ \\
\hline $\begin{array}{l}\text { Diastolic pressure } \\
(\mathrm{mm} . \mathrm{Hg})\end{array}$ & $74.1 \pm 8.1$ & $120.9 \pm 19.5$ & 10.090 & $p<0.001$ \\
\hline $\begin{array}{c}\text { Blood sugar } \\
\text { before insulin } \\
(m g m . \%)\end{array}$ & $82.4 \pm 9.4$ & $86.7 \pm 12$ & 1.274 & Not significant \\
\hline Rate of decrease & -1.7488 & -1.8300 & 0.677 & Not significant \\
\hline $\begin{array}{l}\text { Rate of restitu- } \\
\text { tion }\end{array}$ & 0.6201 & 0.3892 & 2.948 & $\mathrm{p}<0.01$ \\
\hline
\end{tabular}

* Values given for the rate of decrease and the rate of restitution of the blood sugar are the regression coefficients calculated from the blood sugar changes during the two phases of the insulin tolerance curves. All other values are expressed as the mean \pm the standard deviation. " $t$ " = Student's ' $t$ ' test of the significance of the difference between the two groups.

\section{METHODS}

Insulin tolerance tests were performed on groups of hypertensive and normotensive subjects by following the blood sugar changes subsequent to the intravenous injection of insulin at a dosage level of 0.1 unit per $\mathbf{k g}$. body weight. In addition to their unrestricted diets, all subjects utilized in this study were given 2 grams of carbohydrate per $\mathrm{kg}$. of body weight on the evening prior to the day of the actual test and all food was withheld from that time until the completion of the test. In previous unpublished studies we found that the ingestion of 2 grams of carbohydrate per $\mathrm{kg}$. body weight was sufficient to replenish the hepatic glycogen stores after their depletion by phlorizinisation. Two blood samples were drawn for determination of the fasting blood sugar. Following the injection of insulin, blood samples were withdrawn at 15, $30,45,60,90$, and 120 minute intervals. The glucose content of the samples was determined by the Nelson modification of the Somogyi procedure (16).

In the choice of the subjects, care was exercised to exclude any individual with laboratory or clinical evidence of hepatic disease or endocrine disorder. Only those patients with no evidence of cardiac failure were included in the hypertensive group of subjects. A number of individuals convalescent from non-specific diseases were used in each of the two groups. By means of conventional statistical procedures (17), it was established that the mean body weights, the mean ages, and the mean fasting blood sugars of the two groups were not significantly different. On the other hand, the mean systolic blood pressures (190 for the hypertensive group, 116 for the normotensive group) and the mean diastolic pressures (121 for the hypertensive group and 74 for the normotensive group) were significantly different (Table I).

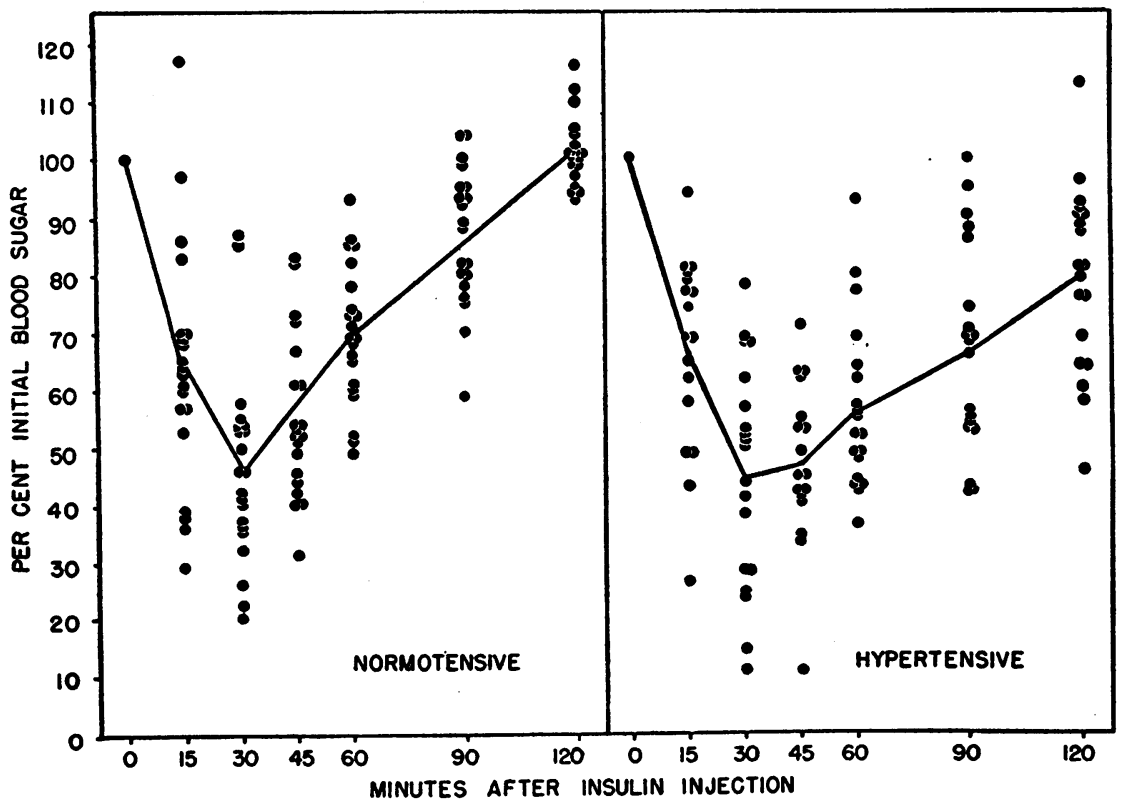

Fig. 1. Blood Sugar Changes Expressed as Per Cent of Initial Level Follow-

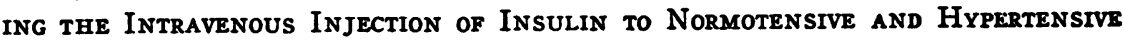
SubJects

The solid line represents the mean for each group of subjects. 


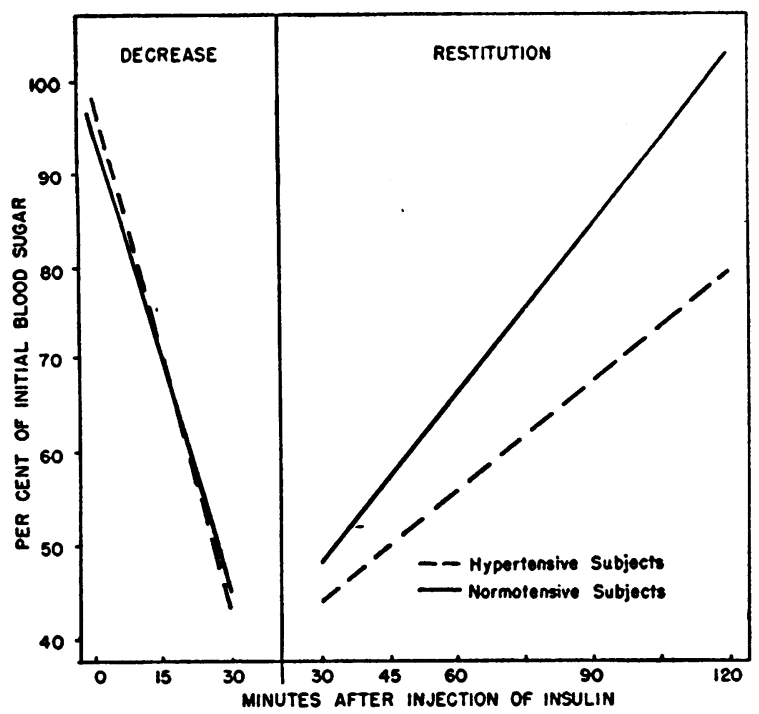

Fig. 2. Regressions of Blood Sugar Expressed as Per Cent of Initial Level on Time During the Phase of Decrease and the Phase of Restitution from HYPOGLYCEMIA

\section{RESULTS}

Insulin tolerance tests were performed as outlined above on 19 hypertensive and 21 normotensive subjects. Although symptoms of hypoglycemia were not uncommon during the course of the test, in no case were they severe enough to warrant termination of the procedure.

The concentration of the blood sugar at the various intervals after the injection of insulin was expressed in terms of its percentage of the preinjection level for each subject (Figure 1). Analysis revealed that the phase of the decrease of the blood sugar occurred during the 0 to 30 minute interval whereas the 30 to 120 minute segment of the curve comprised the phase of restitution. Within each group, the regression of all of the blood sugar changes on time was calculated separately for each phase (Figure 2). Each of the four regressions was found to be highly significant $(\mathrm{p}<0.001)$.

The regression coefficients of the blood sugar on time during each phase of each of the 40 individual insulin tolerance curves were then calculated. This permitted the expression of every curve in terms of the rate of decrease of the blood sugar and the rate of its restitution consequent to the hypoglycemia. The means of these rates for each of the two groups could then be used to characterize the two phases of the insulin tolerance curves for the normotensive and hypertensive subjects. Conventional statistical procedures (Student's ' $t$ ' test) were then applied to estimate the significance of the differences between the mean responses of the normotensive and hypertensive groups.

The analyses revealed that the rate at which the blood sugar decreased after the administration of insulin was the same in both the normotensive and hypertensive groups. However, the rate of restitution of the blood sugar from the hypoglycemic level was significantly different in the two groups of subjects (Table I). Whereas the blood sugar returned to the preinjection level in 120 minutes in the normotensive group, the rate of restitution was significantly delayed in the hypertensive group (Figure 2).

\section{DISCUSSION}

In a report which appeared in abstract form, de Takats and Lasner (18) concluded that patients with hypertension were resistant to the action of insulin. Neutzel and Olsen (19) reported in abstract form that although patients with malignant hypertension were resistant to the action of $1 / 40$ unit insulin per $\mathrm{kg}$. body weight, patients in the benign phase exhibited normal insulin sensitivity. The observations reported herein are not in accord with such conclusions since the rate at which the blood sugar decreased after the administration of a standard dose of insulin was the same in both normotensive and hypertensive subjects, whereas the rate at which the blood sugar was restored to the preinjection level was markedly delayed in the hypertensive group. Actually, the overall effect in the hypertensive group was that of an increased rather than a decreased sensitivity to insulin.

The similarity of the rates at which the blood sugar decreased in both groups of subjects after the administration of a standard dose of insulin suggests that the hypertensive patients did not have an increase in circulating anti-insulin agents. However, the delayed response to hypoglycemia of the hypertensive group may be attributable to a diminution in the reactivity of the anterior pituitary and adrenal cortex or to a diminution in the responsiveness of the sympathico-medulloadrenal system. Since the hypertensive subjects were 
carefully selected in order to exclude those with gross evidences of hepatic or endocrine disorders, and since no evidence of spontaneous hypoglycemia was observed in these patients, it is probable that the delayed restoration of the blood sugar was due to a decreased response of the sympathico-medulloadrenal system rather than to an endocrine or hepatic disorder. However, until more definitive measurements show no disturbance of endocrine activity in hypertension, the mechanism responsible for the delayed restitution of the blood sugar cannot be established with certainty.

A decreased activity of the sympathico-medulloadrenal system is compatible with the presence of hypertension as may be deduced from the many observations that experimental renal hypertension cannot be alleviated by removal of various portions of the nervous system (20). Likewise, the fact that the administration of tetraethylammonium chloride (TEAC) (21) or even sympathectomy does not always reduce the blood pressure of many patients with essential hypertension, indicates that an active sympathico-medulloadrenal system is not essential for the presence of hypertension.

The association of a decreased responsiveness of the sympathico-medulloadrenal system and hypertension does not necessarily indicate any causal relationship. However, such a relationship can be postulated on the basis that a decrease in sympathetic tonus may produce an increase in the sensitivity of the blood vessels to circulating pressor agents. Such a postulate is in accord with the numerous observations on the "sensitization of denervation" (11). It is supported also by the observation that the progressive diminution of the pressor response that occurs in the intact animal on repeated injection of renin (tachyphylaxis), is prevented when the sympathetic ganglia are blocked through the use of TEAC (22). The marked elevation of the blood pressure that frequently follows the administration of TEAC to patients with pheochromocytoma (23) lends further support to the thesis that a decrease in sympathetic tonus can cause a marked sensitization to circulating pressor agents.

\section{SUMMARY AND CONCLUSIONS}

1. Insulin tolerance tests were performed on 19 hypertensive and 21 normotensive subjects. No differences were found in the two groups in regard to the rates at which the blood sugar decreased after injection of a standard dose of insulin.

2. The rate at which the blood sugar was restored from its hypoglycemic state to the preinjection level was found to be significantly delayed in patients with hypertension.

3. The data suggest that there is no increase in the activity of the anterior pituitary gland or adrenal cortex in patients with hypertension but that there may be a decrease in the responsiveness of either the sympathico-medulloadrenal system or of the anterior pituitary and adrenal glands of such patients.

\section{BIBLIOGRAPHY}

1. Young, F. G., The identity and mechanism of action of the glycotropic (anti-insulin) substance of the anterior pituitary gland. Biochem. J., 1938, 32, 1521.

2. Ingle, D. J., The production of experimental glycosuria in the rat. Recent Progr. Hormone Research, 1948, 2, 229.

3. Soskin, S., and Levine, R., Carbohydrate Metabolism: Correlation of Physiological, Biochemical and Clinical Aspects. University of Chicago Press, Chicago, Ill., 1946.

4. Fraser, R., Albright, F., and Smith, P. H., The value of the glucose tolerance test and the insulin tolerance test, and the glucose-insulin tolerance test in the diagnosis of endocrinologic disorders of glucose metabolism. J. Clin. Endocrinol., 1941, 1, 297.

5. Cannon, W. B., McIver, M. A., and Bliss, S. W., Studies on the conditions of activity in endocrine glands. XIII. A sympathetic and adrenal mechanism for mobilizing sugar in hypoglycemia. Am. J. Physiol., 1924. 69, 46.

6. Freeman, N. E., Smithwick, R. H., and White, J. C., Adrenal secretion in man. The reactions of the blood vessels of the human extremity, sensitized by sympathectomy to adrenalin and to adrenal secretion resulting from insulin hypoglycemia. Am. J. Physiol., 1934, 107, 529.

7. de Takats, G., and Cuthbert, F. P., Effect of suprarenal denervation and splanchnic sections on the sugar tolerance of dogs. Arch. Surg., 1935, 30, 151.

8. Dworkin, S., The response of sympathectomized animals to insulin. Am. J. Physiol., 1931, 98, 467.

9. Brouha, L., Cannon, W. B., and Dill, D. B., Blood sugar variations in normal and in sympathectomized dogs. J. Physiol., 1939, 95, 431.

10. de Takats, G., Heyer, H. E., and Keeton, R. W., One surgical approach to hypertension. J. A. M. A., 1942, 118, 501. 
11. White, J. C., and Smithwick, R. H., The Autonomic Nervous System. The Macmillan Co., New York City, 1941, 2nd edition.

12. de Takats, G., Julian, O. C., and Fowler, E. F., The surgical treatment of essential hypertension. IV. Case selection and technique as influencing results. Surgery, 1948, 24, 469.

13. Smithwick, R. H., Surgical treatment of hypertension. Am. J. Med., 1948, 4, 744.

14. Anderson, E., Page, E. W., Li, C. H., and Ogden, E., Restoration of renal hypertension in hypophysectomized rats by the administration of adrenocorticotrophic hormone. Am. J. Physiol., 1944, 141, 393.

15. Page, I. H., The effect of bilaternl adrenalectomy on arterial blood pressure of dogs with experimental hypertension. Am. J. Physiol., 1938, 122, 352.

16. Nelson, N., A photometric adaptation of the Somogyi method for the determination of glucose. J. Biol. Chem., 1944, 153, 375.

17. Snedecor, G. W., Statistical Methods Applied to Ex- periments in Agriculture and Biology. The Collegiate Press, Inc., Ames, Iowa, 1946, 4th edition.

18. de Takats, G., and Lasner, J., The insulin tolerance of the hypertensive patient. J. Lab. \& Clin. Med., 1948, 33, 1487.

19. Neutzel, J. A., and Olsen, N. S., Response to intravenous injection of small quantities of insulin. Federation Proc., 1949, 8, 120.

20. Goldblatt, H., The renal origin of hypertension. Physiol. Rev., 1947, 27, 120.

21. Ferris, E. B., Reiser, M.F., Stead, W. W., and Brust, A. A., Clinical and physiological observations of interrelated mechanisms in arterial hypertension. Tr. A. Am. Physicians, 1948, 61, 97.

22. Page, I. H., and Taylor, R. D., The mechanism of renin tachyphylaxis-restoration of responsiveness by tetraethyl ammonium ion. Science, 1947, 105, 622.

23. La Due, J. S., Murison, P. J., and Pack, G. T., The use of tetraethylammonium bromide as a diagnostic test for pheochromocytoma. Ann. Int. Med., 1948, 29, 914. 